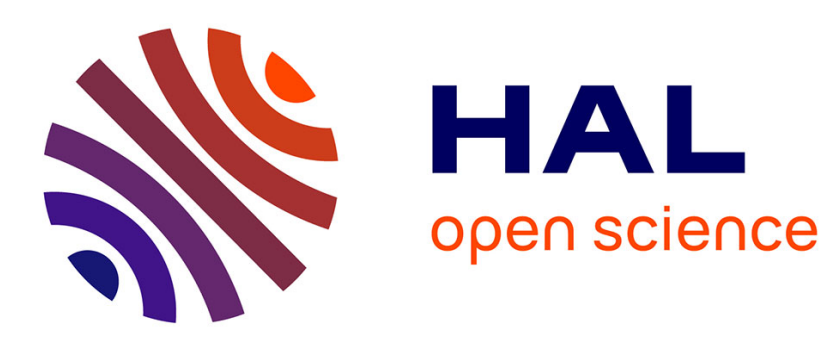

\title{
A. How the intentions of the draftsman shape perception of a drawing.
}

Alessandro Pignocchi

\section{To cite this version:}

Alessandro Pignocchi. A. How the intentions of the draftsman shape perception of a drawing.. Consciousness and Cognition, 2010, pp.XX. 10.1016/j.concog.2010.04.009 . ijn_00488164

\section{HAL Id: ijn_00488164 \\ https://hal.science/ijn_00488164}

Submitted on 1 Jun 2010

HAL is a multi-disciplinary open access archive for the deposit and dissemination of scientific research documents, whether they are published or not. The documents may come from teaching and research institutions in France or abroad, or from public or private research centers.
L'archive ouverte pluridisciplinaire HAL, est destinée au dépôt et à la diffusion de documents scientifiques de niveau recherche, publiés ou non, émanant des établissements d'enseignement et de recherche français ou étrangers, des laboratoires publics ou privés. 
Pignocchi, A. How the intentions of the draftsman shape perception of a drawing. Consciousness and Cognition (2010), doi:10.1016/j.concog.2010.04.009

How the intentions of the draftsman shape perception of a drawing

\author{
Alessandro Pignocchi \\ Institut Jean Nicod, CNRS ENS-DEC EHESS, \\ Pavillon Jardin, 29 rue d'Ulm, 75005 Paris, France
}

pignocchi@hotmail.fr

Keywords: Art and cognition; pictures; drawing; intention; motor simulation

\begin{abstract}
The interaction between the recovery of the artist's intentions and the perception of an artwork is a classic topic for philosophy and history of art. It also frequently, albeit sometimes implicitly, comes up in everyday thought and conversation about art and artworks. Since recent work in cognitive science can help us understand how we perceive and understand the intentions of others, this discipline could fruitfully participate in a multidisciplinary investigation of the role of intention recovery in art perception. The method I propose is to look for cases where recovery of the artist's intentions interacts with perception of a work of art, and this cannot be explain by a simple top-down influence of conscious propositional knowledge on perception. I will focus on drawing and show that recovery of the draftsman's intentional actions is handled by a psychological process shaped by the motor system of the observer.
\end{abstract}




\section{Introduction.}

\subsection{Art and cognitive science: some methodological precautions.}

Art is one of the most complex domains of human activity, notably because it can mobilize nearly all kinds of human abilities and competences. For this reason, many authors consider that cognitive science could be an essential actor in the theoretical investigation of art (Dutton, 2008; Freedberg, \& Gallese 2007; Cavanagh, 2005; Ramachandran \& Hirstein, 1999; Zeki, 1999; Solso, 2005; Dissanayake, 1992). One difficulty with cognitive approaches to art is that art (or artistic experience, or art appreciation) is not a natural kind, indeed it is far from that. If this is the case, it can hardly be addressed in toto with a scientific approach. As a result, cognitive approaches to art are frequently either too narrow or too broad. They are too narrow when they investigate local perceptual phenomena which can occur in front of artworks, but which can also occur in so many other cases of perception that it is unclear how they are supposed to enrich our understanding of art. They are too broad when they try to address very general questions such as art appreciation, for which it is unclear that the tools provided by cognitive science can have relevance, since it is unlikely that the kinds of questions asked could lead to testable hypotheses.

Thus, for a cognitive approach to be optimized, it is important to find "mid-level" questions, neither too broad nor too narrow (Casati, 2003; Pignocchi, in press). At first sight, the topic of intentions might provide such questions. On the one hand, the study of the mechanisms at work when we recover other's intentions is one of the most active fields in cognitive science. On the other hand, the recovery of the artist's intentions is a classical topic for traditional disciplines in the investigation of art, such as philosophy (Davies, 1982; Iseminger, 1992; Levinson, 1993; Livingston, 1998), art criticism, and art history (Baxandall, 1985 ; Gombrich, 1995). The topic of intention is also frequently present, although sometimes only implicitly, in our everyday thinking and conversation about art and artworks. For these reasons, research on intentions in art could argue for a role for cognitive science in pluridisciplinary investigations, as an alternative to proceeding as if the field of art was impervious to serious scientific investigation. Clearly, this viewpoint could help make it explicit how a cognitive approach can enrich our understanding of art.

The topic of intentions, however, is still too wide, and it must be decomposed into more explicit sub-problems. This paper focuses on drawing. In conclusion will suggest some approaches to generalizing the results to other art forms. Drawing seems an interesting object of study for two main reasons. First, as a visual art, drawing already benefits from a rich literature in philosophy and the history of art. Second, as we shall see, it is possible to give a 
psychological account of how a drawing is produced. This will turn out to be helpful, since there is growing evidence in cognitive science that the motor knowledge of an observer plays a crucial role in the perception and understanding of the intentions of others.

Now we have narrowed down the object of inquiry a little, the last preliminary step will be to clearly formulate the problem that is to be addressed.

\subsection{Intentions and perception: the problem.}

Some help is provided by two widely accepted theses in the analytic philosophy of art:

(1) Only information that can be seen in a picture, or that influences the way a picture is seen, has relevance for its appreciation, its understanding, and its evaluation as a picture (Graham, 1994; Lopes, 2005; Wollheim 1987).

(2) The intentions of the artist play some role during the appreciation, understanding, and evaluation of a picture as an artwork (Danto, 1981; Hopkins, 2006; Livingston, 1998; Wollheim, 1987).

These two theses are supposed to be purely descriptive. They do not claim that we should understand, appreciate, or evaluate pictures this way. But that we actually do it this way. I will not provide a defense for these claims here, but it should be observed that they are quite intuitive. It is true that information which has absolutely no impact on the way we see a picture (its weight for instance) does not seem to have much relevance for our experience of this picture as a picture. It is also true that the intentions of the artist - what she wanted to do, how she proceeded, what problem she needed to solve - seem to frequently impact our experience of a piece of visual art.

The conjunction of these two theses implies that, in one way or another, there must be some interaction between recovery of the artist's intentions and the perception of a picture. This last observation allows us to formulate a clear problem which seems both to be addressable with a cognitive approach and strongly related to traditional interrogations about art: what are the psychological mechanisms that allow an observer to recover the artist's intentions, and how does this recovery interact with his perception of the picture?

As said, we will restrict our investigation to drawing. But despite this restriction, the answer to the above question is still likely to be much too complex to be addressed in a single paper. Here, I will develop a general method (which could easily be adapted to the investigation of other art forms) and give the first results obtained using this method.

\section{The Top-Down Theory.}




\subsection{The top-down influence of conscious propositional knowledge: a default theory.}

Authors who have discussed the question of the interaction between intention recovery and perception of pictures have addressed it by endorsing, at least implicitly, a very simple theory which I will refer as "the top-down theory". According to this view, an observer first acquires conscious propositional knowledge (i.e. knowledge which has a form something like that of a sentence) based on what she hears or reads about the intentions of the artist, in addition to the inferences she can perform using her background knowledge and what she perceives by looking at the picture. Once acquired, this propositional knowledge exerts a top-down influence on the way she sees the picture (Hopkins, 2006; Maynard, 2005 p. 191; Walton, 1987 p. 100; Wollheim, 1987 p. 89).

Simple as it is, this theory nevertheless explains many kinds of interaction between the recovery of an artist's intentions and the perception of a picture. Consider A Woman Drinking Tea by Chardin (the example is a painting, but since the top-down theory is supposed to apply to all kinds of pictures, it would apply in the same way to a drawing). Baxandall (1985) notices that Chardin did not paint the reflection of the woman on the teapot. He then informs us that the woman in the picture is Chardin's wife, a few weeks before her death. Baxandall argues that Chardin voluntarily suppressed the reflection to enhance the ghostly aspect of the woman. Contrary to what Baxandall seems to believe, it is implausible that without explicitly noticing it the absence of the reflection would have any effect on our experience of the painting. Cognitive science has shown that anomalies involving represented reflections are generally unprocessed by our cognitive apparatus (Cavanagh, 2005). Nevertheless, once we have read Baxandall's analyses, we start paying attention to the absence of the reflection, and begin seeing it as the result of a precise and meaningful intentional process. From this moment on, the absence of the reflection begins to shape our experience of the painting and, in fact, enhances the ghostly aspect of the woman drinking tea.

For this kind of case, the top-down theory seems adequate. However, intuitively, it seems implausible that the top-down theory could be the whole story about interaction between intentions and perception. Results in cognitive science reveal that conscious propositional knowledge cannot shape perception in all possible ways. More precisely, it appears to be able to shape it in only two ways. First, propositional knowledge can influence experience through attention. The acquisition of some propositional information allows me to consciously direct my attention toward some feature that I would otherwise not have noticed. This is what happens in the above example. Second, propositional knowledge can cause our general recognitional apparatus to detect some basic feature in a visual scene. For instance, if 
someone tells me that I have to find a red triangle in a visual display, this knowledge will preactivate the basic perceptual categories "red" and "triangle" in order to facilitate my detection of a red triangle (Fenske et al., 2006; Pylyshyn, 1999). What propositional knowledge cannot do is create a perceptual category out of nothing. I must already possess the basic categories "triangle” and "red” for the propositional information conveyed by "look for a red triangle” to prepare me to detect a red triangle in the visual display.

Intuitively, again, it seems that recovery of an artist's intentions can shape our perception of a picture in much deeper ways than that. This is particularly clear if we endorse a wide and now quite consensual conception of intentions, according to which the concept of intention covers not only the abstract conscious goals of the artist but all mental states, conscious or not, propositional or not, whose content has played a causal role in the production of the artwork. This concept of intention covers at least both the 'prior intention' i.e. an abstract representation of goals and 'intentions in action', i.e. sensorimotor representations of the concrete goal of each action, which can be assimilated to action plans (Pacherie, 2000; Searle, 1983). Furthermore, it is likely that each of these two concepts also needs further distinctions (Chambon, et al., submitted ; Pacherie, 2008;). This gives us a preliminary idea of the variety of intentions whose recovery can potentially interact with perception of a picture.

The above-mentioned authors who endorse the top-down theory would themselves agree that this theory is insufficient to explain the wide range of phenomena which seem to be imputable to an interaction between the recovery of intentions and the perception of a picture. At least some of them would allow for the intervention of unconscious and/or non-propositional knowledge. However, to the best of my knowledge, there is not even the beginning of an answer in the literature about art to the question of how this would work. And this is precisely the problem which has to be addressed: what might the corresponding psychological mechanisms be like? How can the brain process unconscious and/or non-propositional knowledge about the artist's intentions, in what kind of inferences can this knowledge figure, and how do these processes shape our experience of a picture?

The method I suggest to explore this vast topic is the following: first, find clearly identifiable phenomena which reveal an interaction between recovery of intentions and perception of a work of art and which cannot be explained by the top-down theory. Second, propose testable psychological hypotheses to account for these phenomena. As we shall see, investigating the perception of drawings reveals that some properties of drawings are directly perceived as resulting from the intentional actions of the draftsman. I.e. it will appear that the fact that a 
drawing is produced by a set of intentional actions can shape our perception of it before any retroaction of conscious propositional knowledge.

\subsection{The Problem of Twofoldness.}

Philosophers generally assume that the traces left on a drawing surface by the draftsman's actions influence our experience of it, even if we are explicitly paying attention to its representational properties. In other words, the experience of a drawing includes, in a unitary fashion, its content and the fact that this content is seen via a set of marks laid down in a particular way. This "dual” experience is part of a wider phenomenon sometimes called "twofoldness" (Wollheim, 1987; Lopes, 2005). This dual nature of the drawing experience is problematic for the top-down theory. The top-down theory would explain the perception of the fact that the lines of a drawing are drawn by the attentional orientation of our general recognitional abilities driven by propositional knowledge. We know, more or less, how a drawing is made. This knowledge and the aspect of the lines of one specific drawing allow us to draw some inferences about the way those particular lines have been drawn. Once acquired, this knowledge orients, through attention, our recognitional abilities so that we see these lines as drawn in a particular fashion.

This attentional orientation of our general recognitional abilities can be compared with what happens when we see the famous duck-rabbit picture. We can orient our attention for our recognitional apparatus to process it either as the duck or the rabbit. When the duck is seen, the rabbit does not influence our experience of the picture at all and vice versa. The phenomenon in which we see how the lines of a drawing were made seems quite distinct from the duck-rabbit case. In fact, at least if we accept the phenomenological description generally given by philosophers, the fact that the lines are drawn in a certain way shapes our experience of a drawing even when we are focusing attention on what is represented. For instance, when we see Rembrandt's drawing Hendrijke asleep, we have a joint experience of Hendrike sleeping and of the brush strokes laid down by Rembrandt in a very particular fashion, with their own dynamical properties (Maynard, 2005, p. 209). When we look at a Chinese painting on which bamboo leaves are represented with single very skilful brush strokes, we experience at the same time bamboo leaves and the result of the skilful gestures. No oscillation is required, as in the case of the duck-rabbit drawing.

Of course this argument rests on a first-person phenomenological description whereas the topdown theory is a third-person explanation of a psychological phenomenon. It is true that this kind of rapprochement between different levels of description can be misleading. 
Nevertheless, it seems that a theory which allowed for joint perception of the recognitional properties of a drawing and of the traces on its surface as produced by some intentional actions would be more adequate than the top-down theory which requires oscillation between the processing of two different classes of objects.

\subsection{The Recognition of Dexterity, Spontaneity and the Use of an Intentional Idiom.}

Drawing descriptions frequently employ predicates which refer to complex features of the intentional process of picture production. Such predicates are, for instance, "this drawing has been made with an impressive dexterity", "it is very spontaneous", "the lines of this drawing are energetic”, “vigorous”, “resolute”, “nervous”, or "hesitant” "laborious” and “painstaking”.

The problem for a top-down theory is that the properties involved here seem to be directly seen. More precisely, it seems that I don't have to infer consciously that a drawing is spontaneous before seeing it as spontaneous. I first see that the drawing is spontaneous, and this makes be believe that it is a spontaneous drawing. In other words, the detection of spontaneity seems to happen before the activation of any kind of propositional knowledge about the way the drawing has been done. One reason to believe this is the case is that there is no distinctive perceptual category shared by all drawings made spontaneously which could be activated by propositional knowledge about the intentions of the draftsman. This is made very clear if we notice that it is generally difficult to justify why we say that a drawing is spontaneous, or made with dexterity, we just see it. At first sight, it might appear that some correlation between the above predicates and clearly defined perceptual categories does exist. For instance, the predicate "nervous" seems to correlate with angular shapes. However, it is easy to find nervous drawings with no angular shapes (some drawings by Schiele could provide examples). And this appears to be the case for all of the above-mentioned predicates. Since there are no identifiable perceptual categories associated with these predicates, it seems impossible that the detection of the corresponding qualities rests on the retroaction of propositional knowledge on perception. Thus, there is reason to think that there is a perceptual mechanism which allows an observer to detect certain complex properties linked to the way a drawing has been produced, and which is, at least in part, independent of the preactivation of propositional knowledge.

\subsection{The Recognition of Styles and Influences.}


It is generally assumed that the style of an artist is an aspect of the intentional process of production of a work of art (Gombrich, 1972; Ross, 2003; Walton, 1987). Consequently, the identification of the style of an artist by looking at one of her pictures must be linked to the detection of certain properties related to the way the picture has been intentionally produced. For some drawings, it is easy to recognize the style of the artist even if explaining how we perform this task is not obvious. For instance, it is sufficient to be acquainted with some of Schiele's drawings to be able to recognize any other drawing made by him, even drawings that represent very different subjects from the ones of the drawings we know. Moreover, it is also often quite easy to identify the influences that have shaped the style of a particular artist. For instance, if someone who has had perceptual experience of drawings by Schiele then sees a drawing by Klimt, he will easily notice that there have been influences from one on the other. What is interesting about these examples is that the perceptual cues which allow an observer to perform these tasks are very subtle, and it is not at all easy to state explicitly what they are.

The problem is thus that, at least in certain cases, such as the one discussed here, the identification of style and the detection of influences seem independent of propositional knowledge. We are able to see that a drawing is by Schiele, or that there has been some influence between Klimt and Schiele, but we do not have a distinctive perceptual category associated with the respective style of Schiele or Klimt which could be activated by propositional knowledge which was activated prior to identification of the style of Schiele or of the influences Klimt had on it. As with the recognition of dexterity or spontaneity, this is clear because it is not easy to explain declaratively how we see that a drawing is by Schiele or that there has been influence between Schiele and Klimt, we just see it. Again, it seems that some properties linked to the way a drawing has been made are involved in the recognition of styles and influences, and are perceived without the help of conscious propositional knowledge.

To sum up, for the fact of twofoldness, for the perception of the complex properties linked to the production process discussed in section 2.3 and for the identification of styles and influences the top-down theory is inadequate. These three points support the claim that there must be a psychological process which allows one to see some aspects of a drawing as the result of an intentional process without the prior intervention of propositional knowledge. Since the above phenomena all concern the perceptual recovery of aspects of the intentional action of the draftsman, a first plausible hypothesis is that we are equipped with a 
psychological mechanism which directly cognizes the lines of a drawing as the results of intentional actions of the draftsman.

The psychological literature contains growing evidence that we dispose of mechanisms specialized for the perception and understanding of observed actions which rest, at least in part, on the motor system of the observer. According to these "simulationist" theories, some capacities used in action planning, action production and/or action control are used, in various ways, during action perception and action understanding.

However, the simulationist hypothesis cannot be applied straightforwardly to the domain of drawings. The major problem is that cognitive scientists are generally concerned with situations where an observer sees an agent acting. In the case at work here, the observer does not see the artist acting; he only sees the properties of a drawing, i.e. the static results of the artist's past action.

To determine whether the simulationist hypothesis might be relevant for the understanding of drawing perception, the first thing we need is a psychological theory of drawing production. This is a prerequisite to answering the question of whether the kind of motor knowledge acquired during drawing production can be reused in perception. The next section is dedicated to the elaboration of a psychological theory of drawing production.

\section{Drawing.}

\subsection{Gombrich's Theory of Drawing.}

The best way to develop a theory of drawing production is to start with the quite authoritative theory elaborated by Gombrich (1972). Taken as it is, this theory is not the kind of psychological theory we need, but it will at least give us an idea of the general constraints that should be respected by such a theory. According to Gombrich, the draftsman acquires his drawing skills by learning a set of graphic schemes. A graphic scheme is a very specific piece of knowledge which allows the draftsman to select, in a visual scene, something that he already knows how to draw and to produce the actions needed to draw it correctly. Moreover, a graphic scheme is specific to a visually defined kind of thing. In other words, a graphic scheme which allows a draftsman to represent a thing with a visual aspect cannot be used to draw something else with a different visual aspect. Finally, according to Gombrich, a draftsman learns his graphic schemes primarily through the study of the drawings of other draftsmen.

The goal now is to give a psychological characterization of graphic schemes which respects the general account sketched by Gombrich. In what follows I give one possible psychological 
characterization. Other characterizations are possible as well but I will not consider them here. The principal argument in favor of the characterization of graphic schemes that I propose is that it rests only on very common psychological mechanisms and that it has empirical support. Moreover, the aim of this paper is not to give a general theory of how we learn to draw per se, but rather to put forward arguments suggesting that motor simulation plays an important role in picture perception, particularly in the context of artistic evaluation. The psychological theory of drawing which follows is one of these arguments.

\subsection{Atomic Graphic Schemes.}

Modern theories of action planning are a good basis for a psychological theory of drawing. More precisely, I will use a set of theories, which could be designated under the generic term of "theory of common-coding" which have received strong empirical support. The theory of common-coding groups at least (Hommel et al., 2001; Hommel \& Musseler 2006; Heyes et al. 2005; Hurley, 2008; Wohlschlager et al., 2003). The general assumption of this theory is that perception and action share a common representational substrate. This common substrate is built up by simple associative learning between a motor pattern and its perceptual outcome. When such a common representation is in place, it is used both for action planning and for action perception. During action planning, the subject internally activates a representation of the perceptual outcome she wants to obtain as a result of her action. As this perceptual outcome is automatically associated with a motor pattern which, previously, has allowed the subject to obtain precisely this perceptual result, the relevant motor pattern is automatically activated and ready to be executed. Since, according to this view, action is planned by the activation of a perceptual representation of its expected result, the same representation can be used for the passive perception of the outcome of the same action performed by others. Thus, according to the theory of common-coding, perceiving the result of an action performed by another activates the same internal representation as if we were planning to realize the very same action.

Applying the theory of common-coding to the case of drawing, we could claim that when we use a pencil we build automatic associations between motor patterns and perceptual representations of certain properties of the lines that are produced by these motor patterns. These automatic associations are then used in planning actions which are aimed at producing lines having the corresponding visual properties, as well as in passively perceiving lines drawn by others bearing the same visual properties. 
The empirical literature provides support for the claim that such automatic and bidirectional associations between motor patterns and visual properties of lines do indeed exist. Babcock and Freyd (1988) asked two groups of subjects to copy two series of small abstract handwritten characters. The two series were very similar but for each character in a series the equivalent character in the other series contained a line drawn in the opposite direction (See figure 1 for an example).
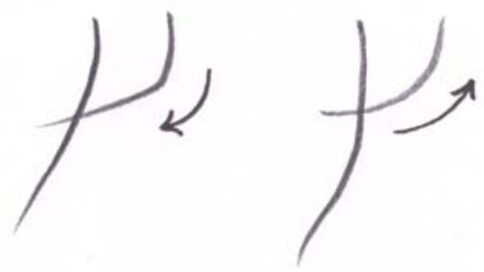

Figure 1 : Authors rendering of the stimuli used by Babcock and Freyd (1988). The arrows indicate the direction in which the strokes have been drawn.

Results show that subjects spontaneously copy the lines in the

direction they were drawn in the model. Moreover, when the subjects are explicitly asked about the direction in which the lines of the models were drawn, their responses are sometime less accurate than their implicit response in the copying task. This difference between performance in the implicit and explicit tasks is strong evidence in favor of an automatic visuomotor association between local visual properties of the line and the direction of movement in drawing. In this experiment, the visual properties of the line which are automatically correlated with motor parameters could be, for instance, variation in the thickness of the line.

Using drawing tasks, Viviani and Stucchi (1992) have shown that in biological movements variations of speed are linked in a law-like way to variations in curvature in production as well as in perception, and that this link is automatic. As the curvature of a movement is retained in the resulting line, it is likely that motor parameters for speed can be recovered automatically by perceiving the lines of a drawing. These results suggest that some local visual attributes of the lines - such as variations in thickness and curvature - are automatically associated with some of the motor parameters involved in their production - such as direction of movement and speed. Pressure has not been tested for. However, as the lines of a drawing retain rich traces of the pressure of the hand, via their pigmentation or thickness for instance, it is reasonable to expect that the same kind of visuomotor associations will be found for pressure. 
Notice that the subjects in the above experiments were not expert draftsmen. This indicates that knowing how to use a pencil - to write by hand or to produce the basic drawings that everybody produces, at least in childhood - is sufficient to build visuomotor associations between the aspect of a line and the motor parameters involved in its production. I will use the term 'Atomic Graphic Scheme', or 'AGS', for these automatic and bidirectional associations between local visual attributes of lines and the motor parameters involved in their production.

\subsection{Molecular Graphic Schemes.}

AGSs explain how we can plan an act of drawing by using a representation of the expected visual aspect of the line. However, AGSs are not sufficient to explain how we can draw, since drawing actions cannot be reduced to the re-enactment of a finite set of previously learned associations. A draftsman is able to produce new actions, i.e. actions he has never seen the result of and has never before produced.

The problem of new actions can be solved by postulating that each act of drawing is planned by dynamically combining different AGSs. A plausible account would be that, when planning an act of drawing, draftsmen bind together different AGSs. The draftsman can do this by activating a representation of the visual aspect of the line, which would lead to a combination of its different visual attributes. Each visual attribute being automatically connected to the relevant motor pattern, the corresponding full motor gesture is consequently planned. Thus, each step of action planning when producing a drawing involves the combination of different AGSs. I will call such a dynamic composition of different AGSs 'Molecular Graphic Schemes', or 'MGS'.

\subsection{Conversion of Molecular Graphic Schemes into Atomic Graphic Schemes.}

The hypothesis that each drawing act is planned by a dynamic combination of different blocks of visuomotor associations has an important consequence: the possible enrichment of the atomic vocabulary of the draftsman via the conversion of MGSs into AGSs. In fact, when a draftsman has found a MGS which produces a desirable visual effect it is likely that he will repeat this same MGS many times in many different drawings. This repetition of an MGS will progressively lead to its automation. That is, the repetition of one MGS will progressively take the process to a point where the different AGSs which compose it will be automatically activated together. At this point, the MGS has become one single block of visuomotor information. As 'being one single block of visuomotor information' is my functional definition of an AGS, we can say that, functionally, the MGS has been converted into an 
AGS. This new AGS can now be combined with other AGSs to form a new MGS, which, if repeated, will convert into another AGS, etc.

By reiterating this loop, the set of AGSs - the atomic vocabulary of the draftsman - becomes richer and more and more complex. The existence of such complex AGSs is supported by an experiment by Flores d'Arcais (1994). The author showed that the order in which the different strokes are executed in a handwritten Chinese character influences the ability of a Chinese reader to recognize it. The visual differences are objectively minimal and do not affect recognition by European subjects. In the same vein, Freyd (1983) was able to show that subjects are better at recognizing an abstract character when the lines that compose it are drawn in the same order as that in which the subject has learned to draw them. This effect depends in part on the local shape of the line at its end. These experiments show that, thanks to practice, the order in which the lines of a character are drawn is a motor parameter that can be recovered by perceiving local visual attributes of the lines. In other words, the order of different gestures is a motor parameter that can be encoded, through learning, in an AGS. A third experiment points in the same direction. Tse and Cavanagh (2000) have shown that when a Chinese subject sees a character of the Chinese alphabet appearing stroke by stroke on a computer screen, she has the illusion that the strokes appear in the direction she is used to drawing them in. This illusion is not found in Western subjects who do not write Chinese. This experiment confirms that the visual aspect of a chunk of strokes can be encoded in a representation which contains motor information. The idea that composite action plans can be automated into a single block of information automatically activated as a whole is also compatible with experiments about handwriting (Thomassen \& Teulings, 1983). These experiments show that the production of a letter which has first to be planned stroke by stroke is after practice planned as a single unit.

\subsection{The Visuomotor Theory of Graphic Schemes.}

We now have the basic ingredients we need to propose a psychological theory of the acquisition of graphic schemes as we learn to draw. According to this theory - the visuomotor theory of graphic schemes - learning to draw follows a three-stage loop:

(1) Use of the pencil builds the first AGSs, i.e. automatic associations between local visual attributes of the line and motor parameters involved in their production.

(2) Effective action planning builds MGS, i.e. dynamic combinations of different AGSs. 
(3) Repetition of the same MGS leads to its automation, i.e. to its functional conversion into an AGS, which can enter into the construction of new MGSs, which can in turn be automated, etc.

Further practice in drawing leads to reiteration of this loop and, progressively, the atomic elements implementing action planning become more and more complex. As a consequence, with practice a draftsman can plan his actions by anticipating more and more complex perceptual results. During the first stages of learning, the draftsman plans his actions thanks to a representation of simple and local attributes of the line, such as its curvature and orientation. After one iteration of the loop he can use a more complete visual representation of the line aspect; then he can use the representation of a small chunk of lines, then again a bigger one, etc. The iteration of the loop leads to the 'distalisation' of action planning: action planning is implemented by a representation of a result that is, each time, more distant from the actual beginning of the action. Theoretically at least, there are no limits to the reiteration of this loop, so AGSs can become very complex. This is in accordance with the observation that expert draftsmen can execute complex drawings quite automatically. Comic strip artists, for instance, seem to be able to draw their characters in a set of prototypical attitudes with only one or very few stages of planning.

The visuomotor theory of graphic schemes respects the constraints laid down by Gombrich. In fact, according to the visuomotor theory of graphic schemes, a graphic scheme contains motor information and, jointly, it contains the visual result that this motor information allows the draftsman to produce. Each graphic scheme is thus very specific to one kind of production visually defined. Moreover, and more importantly, the visuomotor theory of graphic schemes explains why the observation of drawings made by other draftsmen is an essential stage in learning how to draw. In fact, each AGS can be activated internally, during action planning, or externally, during passive perception of the visual result it encodes. Thus, when a draftsman tries to discover a motor plan able to produce a particular visual effect, he can look for this visual effect in the drawings produced by other draftsmen. If the part of the drawing the draftsman is interested in is made up of AGSs he already knows, they will be automatically activated together just by looking at the drawing. The common activation of different AGSs is an MGS. Thus, the observation of a fragment of another's drawing, if this fragment is composed of AGSs the draftsman already masters, will directly activate an MGS, i.e., make the relevant action plan directly available. In other words, AGS are built up by personal practice through associative learning or automation of MGS. On the other hand, the 
relevant MGS can be learned directly through the observation of drawings made by other draftsmen.

At first sight it might seem that the visuomotor theory of graphic schemes is only an account of highly automated drawings, such as those produced by a lazy comic strip draftsman who always draws his characters more or less the same way. But the visuomotor theory of graphic schemes also provides an account of creativity and exploration in drawing. First, of course, new AGSs and new MGSs can always be constructed. Second, a drawing generally requires lots of MGSs, and MGSs can always be combined and sequenced in new ways. Third, crucially, new MGSs can be created by the combination of complex, highly automated AGSs with a totally new AGS. This generative mechanism helps us understand how creativity and exploration can build on already acquired visuomotor knowledge. The use of automated complex AGSs allows the draftsman to anticipate to some extent the visual result that he will obtain and, thus, to know more or less where he is going. The introduction of a new AGS will allow him to modify the habitual result, in order to improve the visual effect or simply to modify it in order to fulfill more abstract goals. Draftsmen rarely change radically their manner of drawing, and when they do it is generally still possible to detect traces of their old approach.

I acknowledge that the visuomotor theory of graphic schemes is speculative. Yet there are reasons to accept this theory at least as a theoretical working hypothesis: (1) it is based on a widely accepted psychological theory of action planning and action perception (the theory of common-coding), (2) it is attuned to Gombrich's account of learning to draw, (3) it uses only very standard psychological mechanisms (associative learning, dynamic combination and automation) the existence of which is not controversial (4) it finds some empirical support in the existing empirical literature and finally (5) it is empirically falsifiable. Notably, a first test for the theory would be to replicate the experiment performed by Babcock and Freyd (1988) testing motor parameters other than direction (speed, pressure and order, for instance). Other possible protocols are discussed below.

All these reasons seem to legitimize the use of the visuomotor theory of graphic schemes as a working tool to make the more general point about simulation in picture perception. The next section makes this point explicit.

4. The Motor Perception Hypothesis (MPH).

4.1. A Psychological Kind of Perception. 
In the last section we learned three things. (1) By using a pencil we build visuomotor associations (the AGSs) that can be subsequently activated automatically when we look at a drawing. AGSs encode visual information which is found in nearly any kind of hand-made drawing, such as the curvature of lines, variations in thickness or pigmentation. Thus, anybody who knows how to use a pencil, if only to write and produce basic drawings, activates some AGSs when looking at a drawing. (2) The complexity of the information encoded by AGSs depends on drawing practice. Thus, when someone who has only rudimentary experience with pencils looks at a drawing he activates AGSs encoding simple motor information such as the direction and the speed of gestures, and the order of some related strokes. By contrast, when an expert draftsman looks at a drawing, she automatically recovers complex motor information such as full sequences of gestures. (3) When the observer pays attention to the production process of the drawing, he binds together the different AGSs automatically activated to form an effective motor plan (the MGS), which can be used, if needed, to reproduce the piece of the drawing to which he pays attention.

These three points are the building blocks of what can be called the 'Motor Perception' (MP) of drawings, i.e., a kind of perception shaped by the motor system of the observer.

When looking at a drawing, the visuomotor system of the observer involved in action planning, whose properties depend on the experience of the observer in the manipulation of pencils, directly picks up visual information in a way which is coherent with action. More precisely, the visuomotor system picks up the visual information as the outcome of someone's action plans. As we shall see later, since the representational structures involved in the MP of drawings are the ones at work during action planning, their external activation through the perception of the properties of a drawing can work backward and allow the observer to recover more abstract intentions which could have motivated the draftsman to produce this drawing (see in particular Hurley (2008)).

The MP defined here has the properties of a standard kind of perception as defined by cognitive psychologists. In fact, it builds on its own primitives which have the particularity of being visuomotor primitives, the AGS. These primitives can be attentionally bound to form a unitary visuomotor percept, equivalent to an MGS, which represents the properties of the drawing as the outcome of the intentional actions of the draftsman. Finally, the information it picks up can enter a more complex informational chain which is not primarily directed toward the semantic categorization of objects, as is standard semantic perception, but towards the intentions of the draftsman that could have been responsible for the production of the visual information perceived. 
MP is thus a kind of perception of the properties of drawing on its own, and is completely distinct from the kind of perception the top-down theory rests on. Before asking if the Motor Perception Hypothesis (MPH) solves the problem encountered by the top-down theory, it is essential to discuss the generality of MP. Notably, it is important to see whether MPH can have relevance to explain some aspect of the perception of drawings produced with a brush or a quill pen, for instance.

\subsection{Two Conditions for MP.}

Thanks to the visuomotor theory of graphic schemes the two essential conditions which determine whether a picture can be an object for MP can be extracted. The first condition is relative to the picture, the second to the observer:

(1) The surface of the picture must retain some visual traces of the motor parameters controlling the actions of the agent who produces it.

(2) The observer must have experience in the use of the very medium used to produce the picture or of some other medium that produces visually similar traces.

At first sight, the second condition seems very restrictive. In fact, a standard observer does not have experience, for instance, of manipulating brushes, quill pens or black leads. She may only have experience with standard pencils, ball-point pens, and felt pens. Thus, the second condition seems to restrict MP to the most standard drawings, at least for a non-artist observer. Nevertheless, this condition is less restrictive than it seems. In fact, the visual information encoded in an AGS cannot be a very strict representation, since different repetitions of the same motor pattern never lead to exactly the same visual result. Thus, there is necessarily some indeterminacy as to just what piece of visual information can activate an AGS. Moreover, traces left by pencils and traces left by many other artistic media, such as quill pens or brushes, share many visual properties. Thus, the perception of the traces left by a quill pen, a black lead pencil or a brush stroke are all likely to activate AGSs which have been learned during the manipulation of regular pencils.

The possible generalization of the MPH to other art forms will be discussed later. For now notice that MP is a matter of degree, and that it is not strictly restricted to drawings produced exactly with the tools the observer is familiar with. Some similarities between the traces left on the surface of the drawing by the actions of the draftsman and the traces left by tools the observer has already used are sufficient to activate a form of MP.

\subsection{MP and Twofoldness.}


As seen in section 2.2, there is a tension between the top-down theory and the possibility of a joint experience of the content of a drawing and of the way it is drawn. The top-down theory requires that in order to perceive some properties of a drawing as drawn we must attentionally orient our general recognitional system toward them. Thus, the top-down theory would require an attentional switch from what is represented to the perception of the lines or the brush strokes as produced by an intentional agent, which seems in conflict with the phenomenological data.

The primitive components of MP are activated automatically, without a need to pay specific attention to the way the picture has been produced. Thus, certain basic properties, for instance visual properties of the brush strokes, can shape our experience of a picture even if we are explicitly attending to its representational properties. Moreover, MP is supported by the visuomotor system involved in action planning and in action perception, not by the perceptual system dedicated to semantic categorization. As nothing prevents these two systems from working together, the properties perceived via MP can influence our experience of a picture even if, at the same time, the system for semantic categorization is occupied with identifying what the picture represents. Thus, contrary to the top-down theory, the MPH is perfectly compatible with a joint experience of the content of a drawing and of some aspect linked to its production process.

\subsection{The MP of Complex Features of the Production Process of a drawing.}

The second problem for the top-down theory is that it hardly explains how we detect properties such as dexterity, spontaneity, or other features of the process of production. According to the MPH, MP is a kind of perception attuned to the visual attributes of a picture which result from the intentional actions of the artist. Thus, for MP, the visual attributes of a picture that reveal aspects of its process of production, such as dexterity or spontaneity, are not just complex visual features which have to be recognized, as the top-down theory prescribes. They are precisely the kind of attributes this mode of perception is naturally attuned to. Moreover, the fact that we have difficulties in justifying why we think a picture was made with dexterity or spontaneity is coherent with the MPH. During MP the observer re-enacts in his own visuomotor system some moments of the production process of the picture. It is this simulation which allows him to detect complex features of the production process such as dexterity, spontaneity, nervousness, energy, or hesitation and laboriousness. The MPH is thus much better suited than the top-down theory to explaining detection of the complex features linked to the process of producing the picture. 
Crucially, the explanation provided by MPH can be tested empirically. One possible experimental task would be to ask subjects to evaluate certain aspects of the production process of a drawing, such as some basic form of dexterity. It might be hard to find an objectively measurable parameter, but the time spent practicing drawing could provide a starting point. The experiment would contrast the performance of expert draftsmen with those of art critics who should have (at least) the same level of propositional knowledge and purely visual knowledge as expert draftsmen, but poorer visuomotor knowledge. The prediction would be that expert draftsmen will detect more accurately than non-draftsmen art critics certain properties linked to the production process of the drawing. A refinement would consist in artificially manipulating local aspects of the line supposed to be picked up by MP (An example of what these artificial manipulations could be like can be found in the work of Freyd (1983)). The prediction is that these manipulations will affect the performance of expert draftsmen more than that of art critics.

This kind of experiment could profit from the work of Aglioti and his collaborators (Aglioti, et al., 2008). The authors contrasted the performance of professional basketball players with that of coaches and sports journalists in predicting the success of free shots at the basket. The results indicate that professional basketball players perform better than coaches and sports journalists. The overall results reveal a crucial role of motor knowledge in the realization of this apparently visual task.

\subsection{MP and the Recognition of Style and Influences.}

The last problem for the top-down theory concerns our ability to identify aspects of style and influences. In particular, the top-down theory encounters difficulties precisely with the detection of the properties of styles and the influences linked with the way an artist performs her actions, because these properties are manifested in the picture by quite subtle visual attributes not directly related to semantic categories. Here again, MP seems in a much better position than the top-down theory to explain these phenomena, since the visual attributes that reveal specifics of how the artist acted are precisely the kind of features to which MP is attuned. Thanks to the detection of these visual attributes and to the re-enactment of aspects of the intentional actions of the artist, MP allows the observer to directly detect subtle similarities in the kind of actions which led to the production of different drawings. Those similarities come from the fact that the different drawings were produced by the same draftsman (in the case of style recognition), or by two draftsmen one of whom, at least, influenced the other (in the case of the detection of influences). 
In the case of the detection of influences, the explanation provided by the MPH can even go a bit further. As has been shown, the visuomotor theory of graphic schemes suggests that some relevant action plans are learned directly through the observation of drawings made by others. The observation of a drawing automatically activates some AGSs involved in the production of this drawing, which can combine into a MGS (an action plan). This MGS can then be directly reused by the observer to produce her own drawings. In other words, the visuomotor theory of graphic schemes describes a possible visuomotor pathway for a direct diffusion of influences. When an observer identifies those influences she activates, in her own visuomotor system, thank to MP, the same kinds of visuomotor representations which have been propagated, via a visuomotor pathway, from one draftsman to the other. This could be, for instance, the mechanism at work when we identify similarities between the drawing styles of Schiele and Klimt. Thus, the MPH solves the three problems faced by the top-down theory.

Again, the crucial point is that the explanation provided by MPH to explain the recovery of some aspects of style and influences can be tested experimentally. To measure the recognition of style, the experiment would proceed by asking subjects to sort drawings by grouping together those produced by the same draftsman. For evaluation of the recognition of influences, the task would be to ask subjects to sort together drawings where one as served as a model for the other. The prediction is that expert draftsmen will perform better on each of these tasks than art critics. Here also, an additional prediction is that the artificial manipulation of some local aspects of the line supposed to be picked up by MP will affect the performance of expert draftsmen more than that of art critics.

\section{MP and the recovery of the artist's intentions}

MPH suggests that the manipulation of some tools such as pencils, ball-point pens, and felt pens equips the visuomotor system of the observer with representational capacities allowing him to directly pick up the information on a drawn surface as the result of possible action plans of the draftsman. The information is organized from the beginning of the observational process in a way coherent with action, before there is any kind of feedback from propositional knowledge. The corresponding percept opens a route to recovery of the draftsman's intentions, where the mechanisms that are involved in action planning work backward, from the perception of an action result toward the inference of more abstract intentions. What might this route be like?

At the level described by MP there is, in the visuomotor system of the observer, a one to one correlation between a perceived result and a possible action plan (an MGS). Thus, at this 
level, the information on the drawing is organized as a set of results of actions the observer himself would have produced. At this level, MP can provide quite reliable information for such basic motor parameters as the speed of the hand, or the pressure or direction of the movement. For more complex parameters, MP is much less reliable, especially if the observer is not himself an expert draftsman. For instance, the observer may recover as the outcome of an action plan what was for the draftsman only one aspect of a much more complex action plan.

When the level of intentions in action is passed, the one to one correlation disappears: one action plan can be activated by many different prior intentions. As the process goes up through levels of abstraction, i.e. as the intentions recovered are more and more abstract, additional knowledge (propositional or not) constrains the space of possible intentions (this model is inspired by Kilner at al. (2007a), Kilner et al. (2007b) and Chambon et al. (submitted)). The motor plans recovered directly by MP are just the first ingredient of this inferential chain allowing the recovery of intentions at different levels of abstraction. In this chain, the information recovered by MP can play a crucial role even if the recovered motor plan corresponds only very partially to that of the draftsman and even if the recovered information conflicts, at some point of the chain, with other kinds of knowledge.

Consider again the Rembrandt drawing Hendrijke asleep. For a non-expert, each brush stroke is probably perceived as an independent action plan. The non-expert possibly feels that he could have produced more or less the same kind of action. At some point, however, the perception of a set of independent action plans will conflict with perception of the global coherence of the brush strokes, which gives the drawing its representational quality. The nonexpert could have produced, more or less, each of the brush strokes by planning them independently, but in doing so he would certainly not have obtained the same global visual effect, except by a miracle. The reason for this is that what the non-expert recovers as a set of independent action plans were for Rembrandt only small sub-parts of a much more complex action plan allowing him to anticipate and control, to some extent, the visual outcome of a much more complex sequence of gestures. This discrepancy between the recovered action plans and other kinds of information (in this case the representational qualities of the drawing) can itself provide information about the intentional process of production. In the present case it is, possibly, partly responsible for the impression of dexterity.

A discrepancy between recovered action plans and more contextual knowledge also exists , for instance, with the perception of an engraving. At the level of MP, because of many similarities between the traces perceived on the surface of the engraving and the kind of traces 
that can be produced with a pencil, a non-expert observer will probably recover a quite simple action plan. And if he does not have knowledge of how an engraving is made, he will remain with this perception. Otherwise, at some point, a conflict will arise between his knowledge about the way engravings are produced and the perception of simple motor plans at the level of MP.

Some artists have very deliberately played with this kind of conflict. An extreme example is provided by Robert Rauschenberg's Factum II. Rauschenberg first produced Factum I which contains, among other things, quick brush strokes and paint splashes. Then he painted Factum II, a careful and meticulous reproduction of Factum I, a kind of "trompe l'oeil" of Factum I. At the level of MP, both Factum I and Factum II are perceived as produced by quick brush strokes and paint splashes. But for Factum II MP conflicts with contextual knowledge, and this conflict is the starting point of an inferential chain that allows the observer to come up with a hypothesis about Rauschenberg's intentions.

In other situations artists manage instead to avoid such conflicts and allow observers to recover, using MP, action plans that are much simpler than the plan the artist actually used. This is the case of some comic strip artists, who want their drawing to give an impression of spontaneity and quick execution. They want it to give the overall impression that the drawings were produced as the story occurred to them, as a kind of improvisation. They want to give this impression even if, in fact, both the scenario and the drawings were the outcome of a long and carefully planned process. In this case, their efforts are dedicated to imitating the cues that will activate, in the mind of the observer, recovery of a very spontaneous production process, and to covering all traces of the actually painstaking process.

It is thus clear that the precise role played by the visuomotor information recovered through MP is highly variable. It depends on many aspects linked to the kind of drawing and to the visuomotor knowledge of the observer. In some cases the action plans recovered through MP are coherent with other kinds of knowledge. In some cases they conflict with it. But, in all cases, it would seem that the MPH must be an essential ingredient of a psychological theory that can explain the interaction between the recovery of the draftsman's intentions and the perception of a drawing.

\section{Conclusion}

The problem of the interaction between recovery of the artist's intentions and the perception of her work seems to be a good choice if we want to explore possible synergies between cognitive approaches and more traditional approaches to the study of art. The general method 
proposed here consists in finding precise phenomena which cannot be explained in terms of a top-down influence of conscious propositional knowledge on perception, and developing testable hypotheses about the psychological mechanisms that may be involved. This method, applied to drawing, has led us to formulation of the MPH, according to which some properties of drawing are directly picked up as the result of possible action plans. This kind of perception is shaped by the visuomotor knowledge of the observer.

Defending the MPH in no way implies a rejection of the importance of propositional and topdown processing in the observer of a work of art. It is clear that propositional conscious knowledge plays a crucial role in an explanation of the interaction between the recovery of artist's intentions and the perception of a drawing. The MPH is just a first step towards the investigation of the precise contribution of various kinds of knowledge in the appreciation of works of art. More precisely, MPH paves the way for an investigation of procedural knowledge, i.e. knowledge of the "knowhow" variety. It suggests that the procedural knowledge acquired during the personal practice of activities which share relevant similarities with aspects of the production process of the perceived artwork can shape our experience of it, and, in particular, lets us experience it from rather early and automatic stages of its perception as intentionally produced. It is hard to say how general this result may be. For now, it is only reasonable to observe that it seems highly plausible that a dancer does not have the same experience when observing dance as a non-dancer (Calvo-Merino et al., 2005; Montero, 2007), that a musician hears musical performance in a particular way, and that the way a scenarist experiences movies and novels is different from the experience that a film director would have, itself different from the experience of someone who has never tried to tell a story. It also seems plausible that being used to telling stories - even if only to one's children or friends - might influence the way a piece of narrative art is experienced. More generally, it seems likely that many everyday activities can provide relevant procedural knowledge which could shape the experience of an artwork. Further research will be necessary to understand how the representational abilities acquired when practicing different kinds of activities can be reused in perception, directly represent some aspect of an artwork as produced by some kinds of intentions.

Future research will also have to explore the role played by other kind of knowledge during the interaction between recovery of intentions and perception of art. The method proposed in this paper may be of help: find local phenomena which can be explained neither by the topdown theory nor by the MPH, and develop testable hypotheses about the underlying psychological mechanisms. 
Acknowledgments

I would like to thank Roberto Casati, Dominic Lopes, Tiger Roholt, Vincent Bergeron, Frédérique De Vignemont, Bence Nanay, Valeria Giardino, Richard Carter and Dan Sperber for helpful comments on earlier versions of this paper. I am also grateful to Bernhard Hommel, Bill Hirstein and an anonymous reviewer of consciousness and cognition for helping me improving earlier drafts of this paper.

References.

Aglioti, S. M., Cesari, P., Romani, M., \& Urgesi C. (2008). Action anticipation and motor resonance in elite basketball players. Nature Neuroscience 11, 1109-1116.

Babcock, M. K., \& Freyd, J. J. (1988). Perception of dynamic information in static handwritten forms. American Journal of Psychology, 101(1), 111-130.

Baxandall, M. (1985). Patterns of intention: on the historical explanation of pictures. New Haven : Yale University Press.

Calvo-Merino, B., Glaser, D. E., Grezes, J., Passingham, R. E., \& Haggard, P. (2005). Action observation and acquired motor skills: an FMRI study with expert dancers. Cerebral Cortex, 15(8), 1243-1249.

Casati, R. (2003) Methodological issues in the study of the depiction of cast shadows. A case study in the relationships between art and cognition. Journal of Aesthetics and Art Criticism, 62(2), 163-174.

Cavanagh, P. (2005) The artist as neuroscientist. Nature, 434, 301-307.

Chambon, V., Domenech, P., Pacherie, E., Koechlin, E., Baraduc, P., \& Farrer, C, (submitted). Differential contribution of prior knowledge to the inference of different types of intentions.

Danto, A. C. (1981). The transfiguration of the commonplace: a philosophy of art. Cambridge, Mass: Harvard University Press.

Davies, S. (1982). The Aesthetic Relevance of Authors' and Painters' Intentions. Journal of Aesthetics and Art Criticism, 41(1), 65-76.

Dutton, D. (2008). The Art Instinct: Beauty, Pleasure, \& Human Evolution. Bloomsbury Publishing PLC.

Dissanayake, E. (1992). Homo Aestheticus: Where Art Comes From and Why. New York: Free Press.

Fenske, M. J., Aminoff, E., Gronau, N., \& Bar, M. (2006). Top-down facilitation of visual object recognition: object-based and context-based contributions. Progress in Brain Research, 155, 3-22.

Flores d'Arcais, G. (1994). Order of strokes writing as a cue for retrieval in reading Chinese Characters. European Journal of Cognitive Psychology, 6, 337-355.

Freyd, J. J. (1983). Representing the dynamics of a static form. Memory \& Cognition, 11(4), 342-346.

Freedberg, D., \& Gallese, V. (2007). Motion, emotion and empathy in esthetic experience. Trends in Cognitive Sciences, 11(5), 197-203.

Gombrich, E. H. (1972). Art and illusion : a study in the psychology of pictorial representation (4th ed.). London: Phaidon.

Gombrich, E. H. (1995). The Story of Art (16th ed.) London: Phaidon.

Graham, G. (1994). Value and the Visual Arts. Journal of Aesthetic Education, 28(4), 1-14.

Heyes, C., Bird, G., Johnson, H., \& Haggard, P. (2005). Experience modulates automatic imitation. Cognitive Brain Research, 22(2), 233-240. 
Hommel, B., \& Musseler, J. (2006). Action-feature integration blinds to feature-overlapping perceptual events: evidence from manual and vocal actions. Quarterly Journal of Experimental Psychology, 59(3), 509-523

Hommel, B., Musseler, J., Aschersleben, G., \& Prinz, W. (2001). The Theory of Event Coding (TEC): a framework for perception and action planning. Behav Brain Sci, 24(5), 849-878; discussion 878-937.

Hopkins, R. (2006). Painting, History, and Experience. Philosophical Studies, 127, 19-35.

Hurley, S. (2008). The shared circuits model (SCM): How control, mirroring, and simulation can enable imitation, deliberation, and mind reading. Behavioral and Brain Sciences, 31, 1-58.

Iseminger, G. (1992). Intention and Interpretation. Philadelphia, Temple.

Kilner, J. M., Friston, K.J. \& Frith, C.D. (2007a). Predictive coding: an account of the mirror neuron system. Cognitive Processing 8, 159-166.

Kilner, J. M., Friston, K. J., \& Frith, C. D. (2007b).The mirror-neuron system: a Bayesian perspective. Neuroreport 18, 619-23.

Levinson, J. (1993). Extending Art Historically. Journal of Aesthetics and Art Criticism, 51(3), 411-423.

Livingston, P. (1998). Intentionalism in Aesthetics, New Literary History, 29, 831-846.

Lopes, D. (2005). Sight and Sensibility: Evaluating Pictures. Oxford: Oxford University Press.

Maynard, P. (2005). Drawing distinctions: the varieties of graphic expression. Ithaca, N.Y.; London: Cornell University Press.

Montero, B. (2007). Practice Makes Perfect: The Effect of Dance Training on the Aesthetic Judge. Unpublished paper delivered at the ASA pacific division meeting.

Pacherie, E. (2000). The Content of Intentions. Mind \& Language, 15(4), 400-432.

Pacherie, E. (2008). The phenomenology of action: A conceptual framework. Cognition, 107, $1: 179-217$.

Pignocchi, A. (submitted). What is art? A methodological framework for a pluridisciplinary investigation. Cognitive semiotics

Pylyshyn, Z. (1999). Is vision continuous with cognition? The case for cognitive impenetrability of visual perception. Behav Brain Sci, 22(3), 341-365; discussion 366423.

Ramachandran, V. S., \& Hirstein, W. (1999). The science of art: a neurological theory of aesthetic experience. Journal of Consciousness Studies, 6, 15-51.

Ross, S. (2003). Style, in The Oxford Handbook of Aesthetics, ed. by Jerrold Levinson, Oxford University Press, 228-244.

Searle, J. R. (1983). Intentionality, an essay in the philosophy of mind. Cambridge; New York: Cambridge University Press.

Solso, R. L. (2005). The Psychology of Art and the Evolution of the Conscious Brain. MIT Press.

Thomassen, A. J., \& Teulings, H. (1983). Constancy in stationary and progressive handwriting. Acta Psychologica, 54(1-3), 179-196.

Tse, P. U., \& Cavanagh, P. (2000). Chinese and Americans see opposite apparent motions in a Chinese character. Cognition, 74(3), 27-32.

Viviani, P., \& Stucchi, N. (1992). Biological movements look uniform: evidence of motorperceptual interactions. Journal of Experimental Psychology: Human Perception and Performance, 18(3), 603-623.

Walton, K. L. (1987). Style and the Products and Processes of Art. In B. Lang (Ed.), Concept of Style (pp. 72-103). Ithaca: Cornell University Press. 
Wollheim, R. (1987). Painting as an Art. London: Thames and Hudson.

Wohlschlager, A., Gattis, M. \& Bekkering, H. (2003). Action generation and action perception in imitation: an instance of the ideomotor principle. Philosophical Transaction of the Royal Society B, 358, 501-515.

Zeki, S. (1999). Inner Vision: an Exploration of Art and the Brain. Oxford, Oxford University Press. 